\title{
Privacy of Wearable Electronics in the Healthcare and Childcare Sectors: A Survey of Personal Perspectives from Finland and the United Kingdom
}

\author{
Johanna Virkki1, Rebecca Aggarwal2 \\ ${ }^{1}$ Department of Electronics and Communications Engineering, Tampere University of Technology, Tampere, \\ Finland \\ ${ }^{2}$ School of Engineering Systems and Management, Aston University, Birmingham, UK \\ Email: johanna.virkki@tut.fi, r.aggarwal3@aston.ac.uk
}

Received 7 January 2014; revised 7 February 2014; accepted 14 February 2014

Copyright $@ 2014$ by authors and Scientific Research Publishing Inc.

This work is licensed under the Creative Commons Attribution International License (CC BY).

http://creativecommons.org/licenses/by/4.0/

c) (i) Open Access

\begin{abstract}
The innovative development of Wearable Electronics (WE) is creating exciting opportunities for application across many industries. Two sectors with high potential are healthcare and childcare. However, it is in these two sectors where the challenges of privacy are presumed to be of the highest. In order to ascertain the personal views of people about potential privacy problems in WE application in these two sectors, interviews with questionnaires were conducted in two different countries: Finland and the United Kingdom (UK). The results indicated that the majority of people in both countries are positive about the use of WE in healthcare and childcare environments. However, when more information is added to be read wirelessly, the attitudes become more negative. In general, the application of WE is more favorable in the UK and the reason as to the difference will make for interesting further research. Several interesting viewpoints and concerns were presented in the interviews. It can be concluded that the implementation of WE in these two sectors will require the collaboration of work on several areas and the development of versatile user studies.
\end{abstract}

Keywords

Childcare; Healthcare; Privacy; Wearable Electronics

\section{Introduction}

Given the importance of addressing ways to provide efficient care for the elderly, children, and people with

How to cite this paper: Virkki, J. and Aggarwal, R. (2014) Privacy of Wearable Electronics in the Healthcare and Childcare Sectors: A Survey of Personal Perspectives from Finland and the United Kingdom. Journal of Information Security, 5, 46-55. http://dx.doi.org/10.4236/jis.2014.52005 
chronic diseases, researchers have started to explore technological solutions to enhance healthcare and social care provision whilst complementing existing services [1]. Within the childcare sector, there is a need to implement systems that monitor the children and automate the safety and security procedures. However, within the healthcare sector, there is a requirement to develop systems which go beyond the identification and monitoring of patients and also include the collection of important data in order to implement preventive care, allow prompt diagnosis of acute complications, and promote understanding of how (pharmacological) therapy is improving patients' parameters [2].

To address the growing needs of the healthcare and childcare sectors, a new generation of clothing and other wearables are being developed, which are able to sense, communicate data, and harvest energy in a nonintrusive way [3] [4]. These innovations fall under the area of Wearable Electronics (WE). The characteristic of ubiquitous monitoring and the wide range of versatile manufacturing methods (screen printing [5] [6], sewing machine and embroidery [7]-[9], copper meshes, conducting textiles, and ribbons [2] [10]-[13], and spraying using conductive paint [12]) has led to high expectations in regard to the potential of WE applications.

Although there are significant benefits in WE applications, the area also has challenges, as illustrated in Table 1. One area that is not addressed, and is of vast importance, is the perception of the people who the technology will be applied. There have been a lot of concerns from the public in regard to wireless sensor technologies but there has not been an investigation into the perceptions of people in regard to WE, particularly in important sectors such as the healthcare and childcare sectors.

This paper explores the personal perspectives of people in reference to WE application in the healthcare and childcare sectors. The research is conducted in both Finland and the UK in order to explore if there is a difference between the two countries. The paper is set out as follows. In section 2, there is a literature review of WE with a focus of its application in the healthcare and childcare sectors. Section 3 explores the main issue of WE (privacy) by exploring the challenges and concerns. It is asserted that further research is required into the perceptions of individuals in regard to WE in healthcare and childcare, and their views of privacy. Section 4 introduces the methodology to investigate this research problem, which is through questionnaires and interviews. In order to gather versatile data and investigate if there are any differences in views, the interviews are carried out in the UK and Finland. The results are presented and discussed in Section 5 and finally the paper concludes with Section 6, the conclusions.

\section{Wearable Electronics (WE)}

\subsection{The Definition of WE}

Wearable electronics and wearable computers appeared in the mid-1990s, when the computer was regarded as

Table 1. List of challenges in WE applications [1].

\begin{tabular}{cc}
\hline Challenge & \\
\hline Hardware & Unobtrusiveness \\
& Sensitivity and calibration \\
Ehysical & Energy \\
& Data acquisition efficiency \\
& Error resilience and reliability \\
& Interoperability \\
& Bandwidth \\
& Security \\
Application & Privacy \\
& User-friendliness \\
& Ease of deployment and scalability \\
& Mobility \\
\hline
\end{tabular}


the ultimate equipment for information processing and thus before tablet computers and smart phones [14]. The concept of wearables, something you're wearing, e.g., clothing, glasses, or watches, is nothing new. However, today's wearables can sense and communicate. In reference [15], WE is defined as "apparel with unobtrusively built-in electronic functions" whereas in reference [16] it is defined as "intelligent assistance that augments memory, intellect, creativity, communication and physical senses". WE in this study is defined by adding electronics in anything wearable. Therefore, the focus in this study is on e-clothes, i.e., clothes with added electronics, and more specifically, an exploration of people's perceptions and not so much in the e-cloth technology itself.

\subsection{WE in Healthcare}

The healthcare sector is very large all across the globe and high costs and large quantity of errors make the industry very challenging [17]. Also, population structures are changing and an increase in the aging population creates a higher demand for healthcare services. The increasing number of patients (many elderly) with chronic diseases (such as heart failures, dementia, and strokes) and the healthcare system adjustment required to cope with the changes have been highlighted as one of biggest challenges by the European Union (EU). Therefore, this research focuses on two member states within the EU; Finland and the UK.

Potential healthcare sector applications of WE can be found, e.g., in patient monitoring, positioning, and identification [18]. In addition, a wireless sensor network (WSN)-based indoor location system to support the nursing staff [19], a radiofrequency identification (RFID) system to track and identify patients in a children's critical care ward [20], body-worn tags for the continuous tracking of human movements in a conventional room [21], and a wearable RFID-enabled sensor node for continuous biomedical monitoring [22] have been introduced.

WE can also offer opportunities to help old people live alone in their homes and systems to detect lifethreatening changes of daily activities of older people have been presented [23]. For example, imagine a system installed in footwear for location tracking and in gloves for activity monitoring [24], as well as an RFID-based fall detection monitoring system, placed into a pair of slippers [25]. WE can monitor the body status by devices that measure heart or brain activity, blood pressure, body temperature, and other body functions [26]. Just to present a couple of examples; the realization of wireless oxygen saturation and heart rate system for patient monitoring [27], a scheme for monitoring the patient's temperature, heartbeat, and pressure [28], and a wearable health system for non-invasive and wireless monitoring of physiological signals [29] have been introduced, which opens up a realm of possibilities when addressing the issues within the healthcare sector for coping with chronic diseases and an aging population.

In addition to reducing the cost of the operation by replacing the time being hospitalized for recovery monitoring with WE and home-nursing, it is also possible to increase the patient's physical activity, and thus also speed up recovery. In the future, the importance of home-nursing is expected to grow in general, and the freedom of movement achieved by WE is especially significant in home nursing [30].

\subsection{WE in Childcare}

In childcare applications, WE could automate the children security and safety and thus provide help to nurses. For example, in emergency situations, use of WE can ensure everyone is safely evacuated and it can provide accurate child and nurse counts for daily management. A single cloth can keep the data of a child (e.g. name of the child and parents, age, kindergarten group, allergies, etc.), allowing the nurses easy access to vital information.

Interesting studies have already been conducted. In one proposed system, RFID tags were embedded in the costumes of the children in order to automate the security supervision and to provide integration with the current security management system for the kindergarten [31]. Another study proposed a system solution based on RFID to be deployed in schools. The system registers arrival and departure times of pupils, and sends that information to parents via mobile phone and/or e-mail [32]. RFID technology was also deployed in a kindergarten environment for indoor positioning to provide a helping hand to nurses [33]. In Finland, all children under seven years old have the right to have daycare organized by municipalities either on a full-time or part-time basis. Compulsory education starts in the year when a child becomes seven years of age and in the previous year the child will participate in pre-primary education in a pre-primary school. In the UK, full-time education is compulsory for all children aged between five and seventeen with a child beginning primary education during the 
school year he or she turns five.

\section{WE and Privacy}

Information privacy is the right of an individual to exercise control over the collection, use, disclosure, and retention of his or her personal information. One of the most important challenges in adopting, and most of all, convincing the actual users to adopt WE in healthcare and childcare environments, is the protection of privacy. The fact that wireless systems can track users' actions, behaviors, and on-going preferences, creates a deterrent to the adoption of a ubiquitous healthcare or childcare system [34]-[37].

One study asserts that during a test of the iPod jacket, the most important adoption factors were convenience and compatibility, and the least important ones were perceived social prestige and observability [38]. It was mentioned that this finding might not be intuitive considering that potential consumers of this kind of WE are thought to be greatly influenced by external forces, such as peer pressure, trends, and perceived social prestige. When moving in personal spaces, such as at home, the bedroom was found to be the most private place that people would not want to be monitored [39]. Therefore, there is an imaginary line as to what is deemed acceptable and what is not when it comes to privacy, and this can often be ambiguous and challenging to define.

When exploring into privacy issues in the healthcare sector, the willingness of older adults to share health or activity data with their doctor or family members have also been measured [40] and over $72 \%$ of participants reported acceptance of in-home and computer monitoring and willingness to share the data with their doctor or family members. However, $60 \%$ reported concerns related to privacy or security and these concerns increased after one year of participation. It was concluded that involvement in this in-home monitoring study raised awareness about the potential privacy risks of the technology [40].

Although the views highlighted some concerns in regard to privacy, independently living elderly individuals were asked to discuss their perceptions and concerns towards the likelihood of using a WSN-based healthcare system in their home [41]. The results in this study indicate that independence is highly valued by elderly people and any technology that can prolong independence, tends to be highly regarded. Thus, for example the privacy of health data might not be as vital as usually considered. Also, according to the participants in a similar study, the results suggested strong acceptance of the concept of home health monitoring and the technology to make the system work [42]. The perspectives for WE in Finland were already collected in a previous study by interviews and an Internet forum survey [43]. Several important points to consider before the implementation of WE for healthcare and childcare environments were found:

- safety of children,

- individual privacy of people,

- practical issues to consider when embedding electronics to clothes, and

- usability of already existing mobile devices for such future applications.

In a study where opinions on individual privacy were collected from China and Finland, the application of Internet of Things to personal health was identified as the least problematic amongst all the applications [44]. It was stated that in the healthcare sector, the most important thing is that all the vital information is available when it is needed. Therefore, it is clear that concerns of privacy within the healthcare sector are very unclear and vary due to age, status (married/single) and potential benefit application (help to improve health or live independently). This requires further investigation and particularly views within the childcare sector where there are no published results of perception within the EU area.

This research develops on the areas addressed in this section and Section 2, filling a gap in the literature in regard to WE application in the healthcare and childcare sectors. The goal is to gather and compare the personal views of people about privacy in WE application from Finland and the UK in order to provide an account of the perceptions and highlight any potential barriers which may arise in regard to further development and application of WE (in healthcare and childcare).

\section{Methodology: Questionnaires and Interviews}

In this study, 45 people, 24 from Finland and 21 from the UK, were interviewed. The interview included the questionnaire (shown in Table 2) and a chance for free comments. The personal interviews were conducted by an associate of the researcher and they took place either at the interviewees working facility, home, or at a neutral, public place. Some of the interviews were done by private (e-)mails between the researcher and the inter- 
viewee. All these interviews thus had more flexibility than only a paper survey as both the researcher and the interviewee were able to ask for clarification. The genders and ages of the interviewees from both countries can be seen in Table 3.

\section{Results and Discussion}

The results (proportion of "Yes" and "No" responses) for the questions 1A and 1B are presented in Table 4. According to our results, 37 out of the total 45 interviewees would be willing to wear hospital clothes that would allow wireless reading of their name and patient number (Situation 1A). The results were similar among people from the UK and Finland and among female and male participants. If, in addition of wireless reading of the name and patient number, the hospital clothes would allow wireless reading of medical and medication records (Situation 1B), 26 out of the total 45 interviewees would be willing to wear the clothes. It can be seen that the Finnish participants are more negative towards wearing these clothes than the participants from the UK. This difference can be clearly seen in Figure 1, where the percentages of answers are presented to make the results more comparable.

The results for how worried would the interviewees be about the individual privacy in these two situations can be seen in Figure 2. In this study, the individual privacy refers to the evolving relationship between the technology and the legal right to, or public expectation of, privacy in the gathering and sharing of data about one's self. As can be seen, in both Finland and the UK, the female interviewees are more worried; the average values of results how worried would the interviewees be about the individual privacy (scale 1 - 5) are higher in both situations $1 \mathrm{~A}$ and $1 \mathrm{~B}$.

It can also be seen in Figure 2, that the average values for the worry about individual privacy in situations $1 \mathrm{~A}$ and 1B were: 2.25 and 3.38 in Finland, respectively, and 2.10 and 2.48 in the UK, respectively. This asserts that as the amount of user information on the clothes increases, the worry about the individual privacy gets stronger. However, in either situation, the worry cannot be considered extremely strong (scale 1 - 5). If we compare the results from Finland and the UK, it can be seen that the people in Finland are more worried about their individual privacy than the people in the UK. Unfortunately this questionnaire gives no further information on the possible reasons behind this. This interesting result definitely requires more research in the next study.

In free comments, WE in hospitals were, in general, considered useful, and people were "not too worried about basic information being read". It was, e.g., pointed out that such clothes may prevent mix-ups of patients.

Table 2. Questionnaire of this study.

1. Would you be willing to wear hospital clothes that.

1(a). Would allow wireless reading of your name and patient number for those taking part into your care? (Yes/No)

1(b). In addition to wireless reading of your name and patient number, would allow wireless reading of your medical and medication records for those taking part into your care? (Yes/No)

2. How worried would you be about your individual privacy in situations $1 \mathrm{~A}$ and $1 \mathrm{~B}$ ? (Scale $=1-5$, where $1=$ not worried at all $5=$ very worried $)$

3. Would you be willing to let your child wear clothes in kindergarten that.

3(a). Would allow the nurses to wirelessly read the child's name and kindergarten group? (Yes/No)

3(b). In addition to the child's name and kindergarten group, would allow the nurses to wirelessly read other information, such as age, allergies, legal guardian, or contact information of guardians? (Yes/No)

4. How worried would you be about your child's individual privacy in situations 3A and 3B?

(Scale $=1-5$, where $1=$ not worried at all $5=$ very worried $)$

Table 3. Genders and ages of the interviewees.

\begin{tabular}{|c|c|c|c|c|}
\hline & \multicolumn{2}{|c|}{ Finland } & \multicolumn{2}{|c|}{ UK } \\
\hline & Female & Male & Female & Male \\
\hline Minimum age & 29 & 28 & 15 & 18 \\
\hline Average age & 36 & 38 & 39 & 37 \\
\hline Maximum age & 52 & 61 & 59 & 60 \\
\hline Number of interviewees & 12 & 12 & 13 & 8 \\
\hline
\end{tabular}


Table 4. Results (answers "Yes” and "No") from situations 1A, 1B, 3A, and 3B.

\begin{tabular}{|c|c|c|c|c|c|c|}
\hline & & Yes/No & $1 \mathrm{~A}$ & 1B & $\mathbf{3 A}$ & 3B \\
\hline \multirow{6}{*}{ Finland } & \multirow{2}{*}{ Female $(\mathrm{N}=12)$} & Yes & 9 & 6 & 10 & 1 \\
\hline & & No & 3 & 6 & 2 & 11 \\
\hline & \multirow{2}{*}{$\begin{array}{c}\text { Male } \\
(\mathrm{N}=12)\end{array}$} & Yes & 10 & 4 & 10 & 6 \\
\hline & & No & 2 & 8 & 2 & 6 \\
\hline & \multirow{2}{*}{$\begin{array}{c}\text { All } \\
(\mathrm{N}=24)\end{array}$} & Yes & 19 & 10 & 20 & 7 \\
\hline & & No & 5 & 14 & 4 & 17 \\
\hline \multirow{6}{*}{ UK } & \multirow{2}{*}{ Female $(\mathrm{N}=13)$} & Yes & 11 & 11 & 11 & 11 \\
\hline & & No & 2 & 2 & 2 & 2 \\
\hline & \multirow{2}{*}{$\begin{array}{c}\text { Male } \\
(\mathrm{N}=8)\end{array}$} & Yes & 7 & 5 & 4 & 2 \\
\hline & & No & 1 & 3 & 4 & 6 \\
\hline & \multirow{2}{*}{$\begin{array}{c}\text { All } \\
(\mathrm{N}=21)\end{array}$} & Yes & 18 & 16 & 15 & 13 \\
\hline & & No & 3 & 5 & 6 & 8 \\
\hline
\end{tabular}
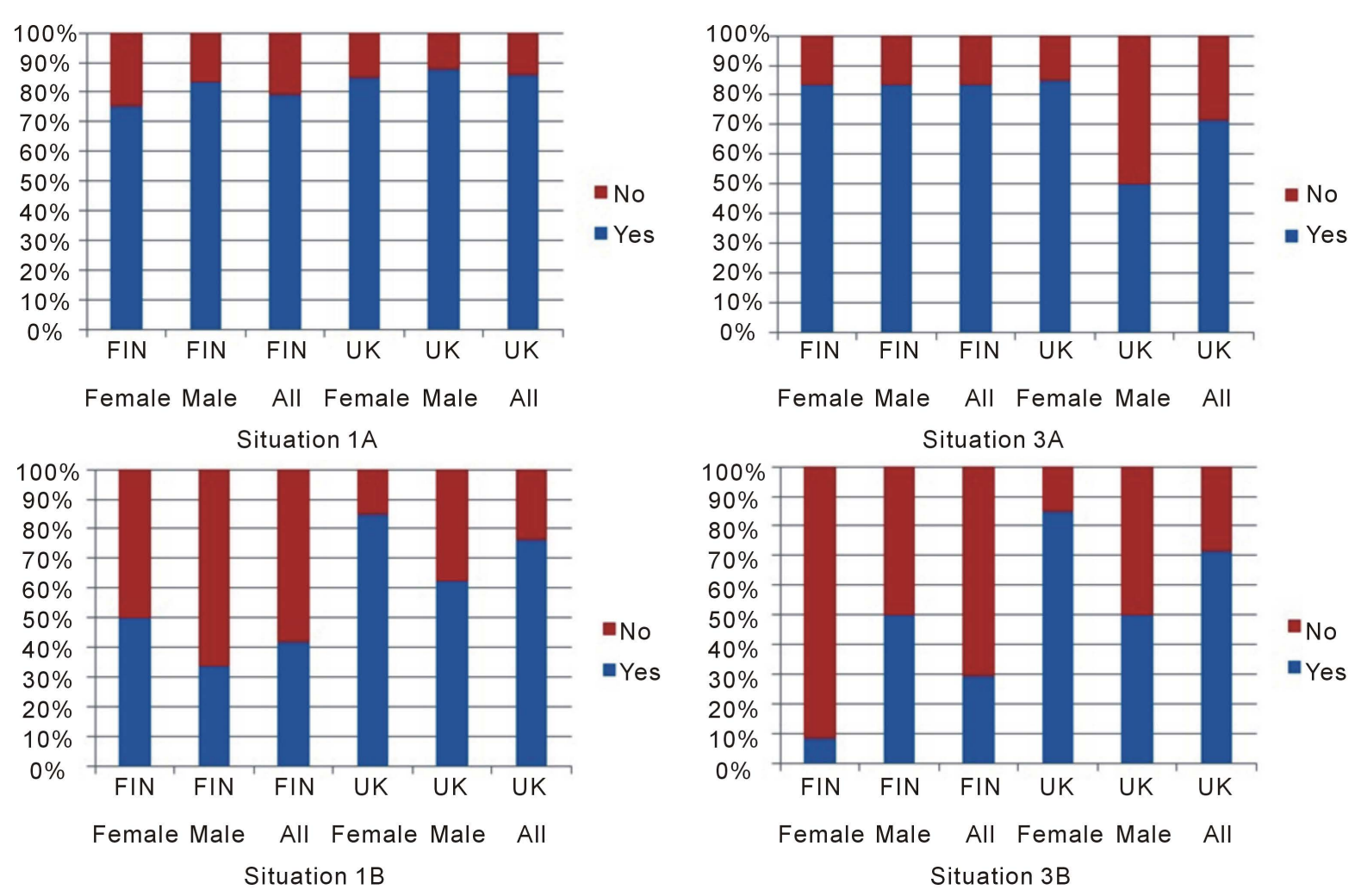

Figure 1. Percentages of answers "Yes" and "No" from situations 1A, 1B, 3A, and 3B.

However, it was specified that availability of medical records is good but they cannot be available for inappropriate people, not even for those working in the hospital. Some people were also worried about the expenses of adapting such technology and some were not sure how quickly the current staff in hospitals could adapt to such a new technology. Also, in some answers, the use of such technology was strongly objected: "It is unnecessary" and "It is too risky and dangerous". Thus, people seem to have several concerns over adaptation of WE in healthcare environment. These results are in line with the conclusions presented in a literature review [45], where it was stated that most systems are described in their prototype stages. Deployment issues, such as implications on organization or personnel, privacy concerns, or financial issues are mentioned rarely, though their solution is crucial in transferring promising systems to a stage of actual field operation. Thus, there is definitely a strong need for further research on the deployment of such systems, including clinical studies, economic and 


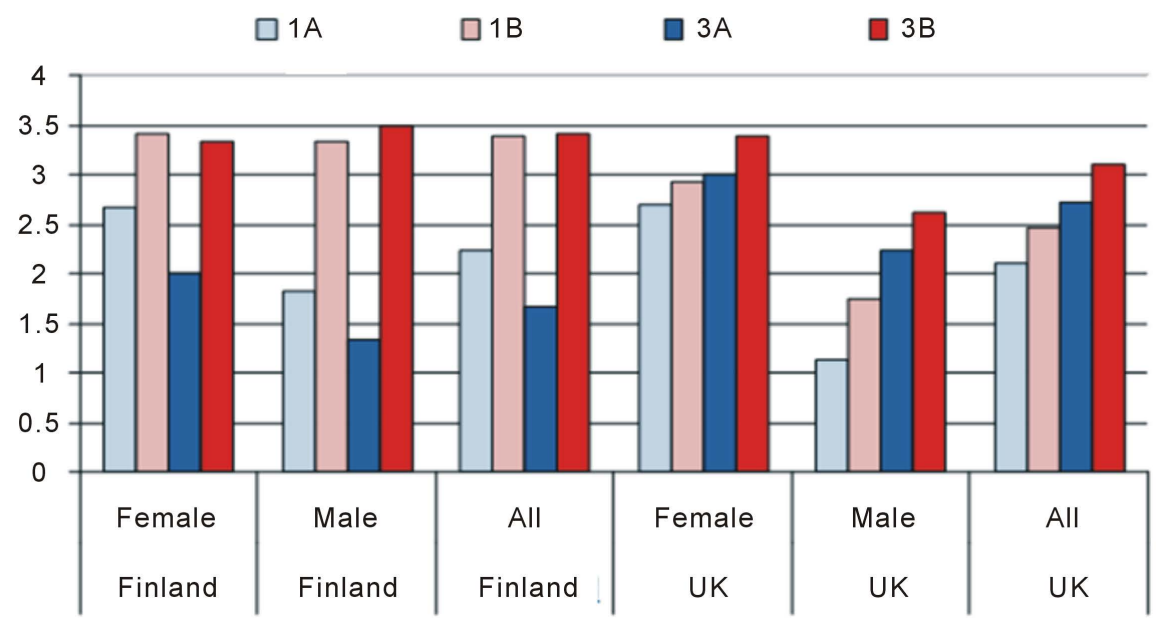

Figure 2. The average values of results how worried would the interviewees be about the individual privacy in situations $1 \mathrm{~A}, 1 \mathrm{~B}, 3 \mathrm{~A}$, and $3 \mathrm{~B}$, scale 1 - 5 .

social analyses, and user studies. The users should embrace the system for full satisfaction.

Table 4 illustrates that 35 out of the total 45 interviewees would be willing to let their child wear clothes in kindergarten that would allow the nurses to wirelessly read the child's name and kindergarten group (Situation 3A). There is no significant difference among people from the UK and Finland and among the female and male interviewees.

If, in addition to the child's name and kindergarten group the clothes would allow the nurses to wirelessly read other information, such as age, allergies, legal guardian, contact information of guardians (Situation 3B), only 20 out of the total 45 interviewees would be willing to let their child wear the clothes. In situation 3B, there was a notable difference when the answers of the female interviewees from the UK were compared to other answers; 11/13 answered "Yes" whereas the other "Yes" results were: 1/12 and 6/12 for the Finnish female and male interviewees, respectively, and 2/8 for the UK male answers. These differences can be clearly seen in Figure 1, where the percentages of answers are presented.

However, as shown in Figure 2, the UK female interviewees gave the average value of 3.38 (Scale 1 - 5) for how worried would they be about the individual privacy in situation 3B. This value is the second highest among all interviewees, right after 3.50 that were given by the male interviewees from Finland. Thus, the female interviewees from the UK are quite worried about the individual privacy of the children but would still allow them to wear wirelessly readable clothes. This is an interesting finding and will be studied further in our next study.

The suitability of WE for children was questioned in many ways in free comments. It was mentioned that if small children are able to rip an electronic component from the clothes, they may eat it, which may cause a serious danger. Also, it was mentioned that the parents need to have the option to make the decision of whether to use such devices in the kindergarten where their children are, stating also that the use of this kind of wirelessly readable clothes has to be voluntary. It was also pointed out that with children it is essential that the caregivers should know all children in person. Some people were not willing to let their children be "wirelessly connected to anything". Thus, as was the case with WE in the healthcare sector, more research on the implications, privacy concerns, and financial issues is needed.

\section{Conclusion}

Many innovative applications of WE have appeared recently and expectations about the possibilities are great. WE has an important application area in the healthcare industry and also a great potential for applications in kindergarten and primary school environments. This paper consists of a literature survey and 45 personal interviews that were conducted to study the thoughts related to the privacy of these WE applications. The results indicate that the majority of people would be contented to use WE but the application is more favorable in the UK than in Finland. The achieved results are in line with the earlier studies that have highlighted some concerns in regard to privacy but with a strong acceptance of different welfare and healthcare technologies. However, this 
study also asserts some interesting new findings and further investigation will be conducted in order to compare the results from other countries to see if and why the personal views differ from country to country. As this paper offers information on the public's perceptions in the UK and Finland, it is useful to those developing wearable electronic applications and those investigating individual's privacy whilst developing the future wireless world.

\section{Acknowledgements}

Johanna Virkki would like to thank The Helsingin Sanomat Foundation.

\section{References}

[1] Alemdar, H. and Ersoy, C. (2010) Wireless Sensor Networks for Healthcare: A Survey. Computer Networks, 54, 26882710. http://dx.doi.org/10.1016/j.comnet.2010.05.003

[2] Niewolny, D. (2013) How the Internet of Things Is Revolutionizing Healthcare. Freescale Whitepaper. http://cache.freescale.com/files/corporate/doc/white_paper/IOTREVHEALCARWP.pdf

[3] Swan, M. (2012) Sensor Mania! The Internet of Things, Wearable Computing, Objective Metrics, and the Quantified Self 2.0. Journal of Sensor and Actuator Networks, 3, 217-253. http://dx.doi.org/10.3390/jsan1030217

[4] Bonfiglio, A. and De Rossi, D. (2011) Wearable Monitoring Systems. Springer, New York. http://dx.doi.org/10.1007/978-1-4419-7384-9

[5] Scarpello, M.L., Kazani, I., Hertleer, C., Rogier, H. and Ginste, D.V. (2012) Stability and Efficiency of Screen-Printed Wearable and Washable Antennas. IEEE Antennas Wireless Propagaton Letters, 11, 838-841. http://dx.doi.org/10.1109/LAWP.2012.2207941

[6] Kellomäki, T., Virkki, J., Merilampi, S. and Ukkonen, L. (2012) Towards Washable Wearable Antennas: A Comparison of Coating Materials for Screen-Printed Textile-Based UHF RFID Tags. International Journal of Antennas and Propagation, 2012, Article ID 476570. http://dx.doi.org/10.1155/2012/476570

[7] Kim, G., Lee, J., Lee, K.H., Chung, Y.C., Yeo, J., Moon, B-H., Yang, J. and Kim, H.C. (2008) Design of a UHF RFID Fiber Tag Antenna with Electric-Thread Using a Sewing Machine. Microwave Conference, Macau, 16-20 December 2008, 4 p.

[8] Roh, J.S., Chi, Y.S., Lee, J.H., Tak, Y., Nam, S. and Kang, T.J. (2010) Embroidered Wearable Multiresonant Folded Dipole Antenna for FM Reception. IEEE Antennas and Wireless Propagation Letters, 9, 803-806. http://dx.doi.org/10.1109/LAWP.2010.2064281

[9] Koski, K., Koski, E., Björninen, T., Babar, A.A., Ukkonen, L., Sydänheimo, L. and Rahmat-Samii, Y. (2012) Practical Read Range Evaluation of Wearable Embroidered UHF RFID Tag. Antennas and Propagation Society International Symposium, Chicago, 8-14 July 2012, 2 p.

[10] Vallozzi, L., Rogier, H. and Hertleer, C. (2008) Dual Polarized Textile Patch Antenna for Integration into Protective Garments. IEEE Antennas and Wireless Propagation Letters, 7, 440-443. http://dx.doi.org/10.1109/LAWP.2008.2000546

[11] Zhu, S. and Langley, R. (2009) Dual-Band Wearable Textile Antenna on an EBG Substrate. IEEE Transactions on Antennas and Propagation, 57, 926-935. http://dx.doi.org/10.1109/TAP.2009.2014527

[12] Matthews, J.C.G. and Pettitt, G. (2009) Development of Flexible, Wearable Antennas. European Conference on Antennas and Propagation, Berlin, 23-27 March 2009, 273-277.

[13] Maleszka, T., Preisner, M. and Kabacik, P. (2009) Meshed Ground Plane Structures for Textile Antennas. European Conference on Antennas and Propagation, Berlin, 23-27 March 2009, 713-717.

[14] Yoo, H.-J. (2013) Your Heart on Your Sleeve: Advances in Textile-Based Electronics Are Weaving Computers Right into the Clothes We Wear. IEEE Solid-State Circuits Magazine, 5, 59-70. http://dx.doi.org/10.1109/MSSC.2012.2232781

[15] Tao, X. (2005) Wearable Electronics and Photonics. CRC Press, Boca Raton.

[16] Ko, F.K., Aufy, A. and Lam, H. (2005) Electrostatically Generated Nanofibres for Wearable Electronics. Wearable Electronics and Photonics, Woodhead Publishing.

[17] Fosso Wamba, S., Anand, A. and Carter, L. (2013) A Literature Review of RFID-Enabled Healthcare Applications and Issues. International Journal of Information Management, 33, 875-891. http://dx.doi.org/10.1016/j.ijinfomgt.2013.07.005

[18] Wang, S.-W., Chen, W.-H., Ong, C.-S., Liu, L. and Chuang, Y.-W. (2006) RFID Application in Hospitals: A Case Study on a Demonstration RFID Project in a Taiwan Hospital. International Conference on System Sciences, 4-7 Janu- 
ary 2006, $10 \mathrm{p}$.

[19] Hsiao, C.C., Sung, Y-J., Lau, S.-J., Chen, C.-H., Hsiao, F.-H., Chu, H.-H. and Huang, P. (2011) Towards Long-Term Mobility Tracking in NTU Hospital's Elder Care Center. IEEE International Conference on Pervasive Computing and Communications Workshops, Seattle, 21-25 March 2011, 649-654.

[20] Iadanza, E. and Dori, F. (2009) Custom Active RFID Solution for Children Tracking and Identifying in a Resuscitation Ward. IEEE International Conference, Engineering in Medicine and Biology, Minneapolis, 3-6 September 2009, 5223-5236.

[21] Occhiuzzi, C., Cippitelli, S. and Marrocco, G. (2010) Modeling, Design and Experimentation of Wearable RFID Sensor Tag. IEEE Transactions on Antennas and Propagation, 58, 2490-2498. http://dx.doi.org/10.1109/TAP.2010.2050435

[22] Yang, L., Vyas, R., Rida, A., Pan, J. and Tentzeris, M.M. (2008) Wearable RFID-Enabled Sensor Nodes for Biomedical Applications. Electronic Components and Technology Conference, Lake Buena Vista, 27-30 May 2008, $2156-2159$.

[23] Safavi, A.A., Keshavarz-Haddad, A., Khoubani, S., Mosharraf-Dehkordi, S., Dehghani-Pilehvarani, A. and Tabei, F.S. (2010) A Remote Elderly Monitoring System with Localizing Based on Wireless Sensor Network. International Conference on Computer Design and Applications, Qinhuangdao, 25-27 June 2010, V2-553-V2-557.

[24] Jung, K.K., Son, D.S. and Eom, K.H. (2009) RFID Footwear and Floor System. World Congress on Computer Science and Information Engineering, 3, 72-75.

[25] Chen, Y.-C. and Lin, Y.-W. (2010) Indoor RFID Gait Monitoring System for Fall Detection. International Symposium on Aware Computing, Tainan, 1-4 November 2010, 207-212.

[26] Pang, Z., Chen, Q., Zheng, L. and Dubrova, E. (2013) An In-Home Medication Management Solution Based on Intelligent Packaging and Ubiquitous Sensing. International Conference on Advanced Communication Technology, Pyeong Chang, 27-30 January 2013, 545-550.

[27] Rotariu, C. and Manta, V. (2012) Wireless System for Remote Monitoring of Oxygen Saturation and Heart Rate. Federated Conference on Computer Science and Information Systems, Wroclaw, 9-12 September 2012, 193-196.

[28] Vijayalakshmi, B. and Ram Kumar, C. (2012) Patient Monitoring System Using Wireless Sensor Based Mesh Network. International Conference on Computing Communication \& Networking Technologies, Coimbatore, 26-28 July 2012, 1-6.

[29] Haahr, R.G., Duun, S., Thomsen, E.V., Hoppe, K. and Branebjerg, J. (2008) A Wearable “Electronic Patch” for Wireless Continuous Monitoring of Chronically Diseased Patients. International Summer School and Symposium on Medical Devices and Biosensors, Hong Kong, 1-3 June 2008, 66-70.

[30] Kellomäki, T., Whittow, W.G., Heikkinen, J. and Kettunen, L. (2009) 2.4 GHz Plaster Antennas for Health Monitoring. European Conference on Antennas and Propagation, Berlin, 23-27 March 2009, 211-215.

[31] Fang, Z., Wei, L., Chen, W. and He, Y. (2012) A RFID-Based Kindergarten Intelligence Security System. IEEE International Conference on E-Business Engineering, Hangzhou, 9-11 September 2012, 321-326.

[32] Krsmanovic, M., Muric, G. and Gospic, N. (2011) Improvement of Children Safety by Using RFID Based Service. Telecommunications Forum, Belgrade, 22-24 November 2011, 130-133.

[33] Lin, C.J., Lee, T.L., Syu, S.L. and Chen, B.W. (2010) Application of Intelligent Agent and RFID Technology for Indoor Position: Safety of Kindergarten as Example. International Conference on Machine Learning and Cybernetics, 5, 25712576.

[34] Feng, H.L. and Fu, W.X. (2010) Study of Recent Development about Privacy and Security of the Internet of Things. International Conference on Web Information Systems and Mining, 2, 91-95.

[35] Kurkovsky, S., Syta, E. and Casano, B. (2011) Continuous RFID-Enabled Authentication: Privacy Implications. IEEE Technology and Society Magazine, 30, 34-41. http://dx.doi.org/10.1109/MTS.2011.942306

[36] Song, W.J., Son, S.H., Choi, M. and Kang, M. (2006) Privacy and Security Control Architecture for Ubiquitous RFID Healthcare System in Wireless Sensor Networks. International Conference on Consumer Electronics, 7-11 January 2006, 239-240.

[37] Choi, S.S., Choi, M.K., Song, W.J. and Son, S.H. (2005) Ubiquitous RFID Healthcare Systems Analysis on PhysioNet Grid Portal Services Using Petri Nets. International Conference on Information, Communications and Signal Processing, Bangkok, 2005, 1254-1258.

[38] Anderson, G. and Lee, G. (2008) Why Consumers (Don’t) Adopt Smart WE. IEEE Pervasive Computing, 7, 10-12. http://dx.doi.org/10.1109/MPRV.2008.64

[39] Choe, E.K., Consolvo, S., Jung, J., Harrison, B. and Kientz, J.A. (2011) Living in a Glass House: A Survey of Private Moments in the Home. International Conference on Ubiquitous Computing, Beijing, 17-21 September 2011, 41-44.

[40] Boise, L., Wild, K., Mattek, N., Ruhl, M., Dodge, H.H. and Kaye, J. (2013) Willingness of Older Adults to Share Data 
and Privacy Concerns after Exposure to Unobtrusive In-Home Monitoring. Gerontechnology, 11, 428-435. http://dx.doi.org/10.4017/gt.2013.11.3.001.00

[41] Steele, R., Lo, A., Secombe, C. and Wong, Y.K. (2009) Elderly Persons' Perception and Acceptance of Using Wireless Sensor Networks to Assist Healthcare. International Journal of Medical Informatics, 78, 788-801. http://dx.doi.org/10.1016/j.ijmedinf.2009.08.001

[42] Mann, W.C., Marchant, T., Tomita, M., Fraas, L. and Stanton, K. (2002) Elder Acceptance of Health Monitoring Devices in the Home. Care Management Journals, 3, 91-98.

[43] Virkki, J. and Raumonen, P. (2013) Perspectives for Wearable Electronics in Healthcare and Childcare. E-Health Telecommunication Systems and Networks, 2, 58-63. http://dx.doi.org/10.4236/etsn.2013.23008

[44] Virkki, J. and Chen, L. (2013) Personal Perspectives: Individual Privacy in the IOT. Advances in Internet of Things, 3 , 21-26. http://dx.doi.org/10.4236/ait.2013.32003

[45] Orwat, C., Graefe, A. and Faulwasser, T. (2008) Towards Pervasive Computing in Health Care-A Literature Review. BMC Medical Informatics \& Decision Making, 8, 26. http://dx.doi.org/10.1186/1472-6947-8-26 